Published in final edited form as:

J Pediatr. 2007 June ; 150(6): 587-591.

\title{
Growth hormone treatment and left ventricular dimensions in Turner syndrome
}

\author{
Lea Ann Matura, PhD, \\ Developmental Endocrinology Branch, National Institute of Child Health and Human Development, \\ National Institutes of Health, Bethesda, Maryland 20892 \\ Vandana Sachdev, MD, \\ National Heart, Lung and Blood Institute National Institutes of Health, Bethesda, Maryland 20892 \\ Vladimir K. Bakalov, MD, \\ Developmental Endocrinology Branch, National Institute of Child Health and Human Development, \\ National Institutes of Health, Bethesda, Maryland 20892 \\ Douglas R. Rosing, MD, and \\ National Heart, Lung and Blood Institute National Institutes of Health, Bethesda, Maryland 20892 \\ Carolyn A. Bondy, MD \\ Developmental Endocrinology Branch, National Institute of Child Health and Human Development, \\ National Institutes of Health, Bethesda, Maryland 20892
}

\section{Abstract}

Objective-To determine if cardiac dimensions were different in girls with Turner syndrome (TS) that did receive growth hormone $(\mathrm{GH})$ vs. those who did not receive $\mathrm{GH}$.

\begin{abstract}
Study design-This was a retrospective, cross sectional study analyzing echocardiograms in 86 females with TS divided into GH-treated $(n=67)$ vs. untreated $(n=19)$ groups. These were subjects with TS participating in the National Institutes of Health protocol between 2001 and 2006.
\end{abstract}

\begin{abstract}
Results-The average age was 16.2 years (range 10-25 yrs) and duration of GH treatment was 4.4 (range 1-14 yrs). The GH-treated group was taller by $\sim 6 \mathrm{~cm}(P=0.004)$ but, cardiac dimensions normalized to body surface area (BSA), including septal and posterior wall thicknesses, left ventricular (LV) mass and LV internal diameters, were not significantly different in the two groups. The fractional shortening index was similar in the two groups. Multiple regression analyses indicated that BSA, but not duration of GH treatment predicted LV dimensions in girls with TS.
\end{abstract}

Conclusions-GH treatment of girls with TS increases stature but does not disproportionately affect cardiac dimensions.

\section{Keywords}

echocardiography; growth hormone; cardiac dimensions; Turner Syndrome

\footnotetext{
All correspondence to: Lea Ann Matura, CRC 1-3330, 10 Center Dr, NIH, 301-451-7164, 301-480-4213 (fax), Bethesda, MD 20892, maturale@mail.nih.gov

Disclosures: The authors have nothing to disclose and there are no conflict of interests. There is no potential conflict of interest, real or perceived, by the authors. The study was supported by a NIH grant. Lea Ann Matura wrote the first draft of the manuscript no honorarium, grant, or other form of payment was given to anyone to produce the manuscript.

Publisher's Disclaimer: This is a PDF file of an unedited manuscript that has been accepted for publication. As a service to our customers we are providing this early version of the manuscript. The manuscript will undergo copyediting, typesetting, and review of the resulting proof before it is published in its final citable form. Please note that during the production process errors may be discovered which could affect the content, and all legal disclaimers that apply to the journal pertain.
} 
Turner syndrome $(45, \mathrm{X}, \mathrm{TS})$ is the most common chromosomal disorder in females, occurring in $\sim 1 / 2500$ live female births (1). Short stature and ovarian failure are the most prevalent findings, but the most medically significant feature is congenital heart disease with a high risk for aortic dilatation and dissection(2-4). In addition to anatomical defects, recent studies have demonstrated electrocardiographic abnormalities and evidence of autonomic and diastolic dysfunction in individuals with TS suggesting a more extensive involvement of the cardiovascular system than previously appreciated (5-8). Although girls with short stature in the context of TS are not usually growth hormone (GH) deficient, the FDA has approved treatment of these girls with recombinant human GH to augment adult height (9-12). Girls with TS are typically treated with GH for $\sim 5$ years using pharmacological doses higher than those normally used in GH-deficient states.

GH actually promotes generalized somatic growth and has significant direct and indirect effects upon the cardiovascular system (13). GH excess resulting from tumors produces an increased heart rate and cardiac output in early stages, followed by cardiac hypertrophy and eventually cardiomyopathy (13). Aortic and mitral regurgitation and arrhythmias are also more prevalent in individuals with acromegaly. GH treatment of GH-deficient individuals increases cardiac mass and output $(14,15)$. Treatment of normal volunteers with GH doses similar to those used in TS $(0.06 \mathrm{mg} / \mathrm{kg} / \mathrm{d})$ increased cardiac output and left ventricular mass in just 4 weeks (16). Finally, treatment of GH-deficient children with exogenous GH has been associated with disproportionate left ventricular growth $(17,18)$. Given the cardiac involvement in TS there has been concern over potential adverse cardiovascular effects of GH treatment. Two echocardiography studies reported "normal" left ventricular morphology and function in GHtreated girls with TS $(19,20)$; however, these studies had no untreated girls with TS for comparison. In the present retrospective study, we examined cardiac variables using echocardiography in girls with TS that received GH treatment and compared them with a group that were not treated.

\section{Methods}

\section{Study subjects}

Study participants were part of the Turner Syndrome natural history protocol which was approved by the National Institute of Child Health Institutional Review Board. All adult participants and parents of minor children gave written informed consent and minors informed assent. The protocol includes studies of bone mineral density, metabolic function and cardiovascular imaging. Study subjects were mainly recruited through notices on the NIH website http://turners.nichd.nih.gov/. Inclusion criteria were phenotypic females older than 6 years who had a 50 cell peripheral karyotype in more than $70 \%$ of cells that demonstrate loss or partial loss of the second sex chromosome.

Consecutive participants between the ages of 10 to 25 and parents of minors were queried on their use of GH. Twenty-one subjects had not received GH treatment compared to 67 who did receive GH treatment. The usual daily dose for our patients was $0.05 \mathrm{mg} / \mathrm{kg} / \mathrm{d}$. Height and weight for each subject were measured by NIH Clinical Research Center (CRC) nurses using a SRScale ${ }^{\circ}$, model SR555, with a height rod. Body mass index (BMI) and BSA were calculated using the DuBois and DuBois formulae.

\section{Echocardiography}

Transthoracic 2D and Doppler echocardiography was obtained on all subjects using commercially available echocardiography machines. The standard parasternal, apical, and subcostal views were obtained with the participants in the left lateral recumbent position. The images were stored digitally and on VHS videotape for analysis. Cardiac measurements were 
performed according to the American Society of Echocardiography guidelines(21). The left ventricular mass (LVM) was calculated using the following anatomically, validated formula, where IVS is interventricular septal thickness, PW is posterior wall thickness, and LVIDD is left ventricular internal diastolic dimension (22): LVM $(\mathrm{g})=0.8(1.04$ [IVS + PW + $\left.\mathrm{LVIDD}^{3}-[\mathrm{LVIDD}]^{3}\right)+0.6$. LVM was divided by BSA $\left(\mathrm{m}^{2}\right)$ to adjust for the effect of body size (23).

\section{Statistics}

Data are presented as means with standard deviations. Group means were compared by ANOVA, with age and body size varaiables as covariates as indicated followed by the Fisher's PLSD test. Multiple linear regression was used to analyze the effects of GH on cardiac dimensions. Analyses were performed using Stat View for Windows, version 5.0.1 (SAS Institute Inc., Cary, NC).

\section{Results}

\section{Study subjects}

There were 86 study subjects aged 10-25 years with reliable information on GH use. Of these, 19 had never used GH and 67 (78\%) had used GH for one year or more. The most common reason for not using $\mathrm{GH}$ was late diagnosis, followed by satisfaction with the patient's height. The average duration of GH use was 4.4 yrs (range $1-14$ yrs). Twenty-three subjects were still taking $\mathrm{GH}$ at the time of their echocardiograms. Of the 67 subjects who received GHtreatment, one had hypertension, $16(24 \%)$ had a bicuspid aortic valve and 2 had a history of coarctation of the aorta. Of the 19 subjects not treated with $\mathrm{GH}$, one had hypertension, 3 (16\%) had a bicuspid aortic valve and none had coarctation. None of the subjects had significant aortic or mitral regurgitation. The two groups were similar in age and body mass, but the GH-treated group was significantly taller (Table I).

\section{Effect of GH on cardiac dimensions}

The effect of GH status on cardiac dimensions is also reported in Table I. All the measures were within the normal age group range. To adjust for body size differences, cardiac dimensions were normalized to BSA. There were no significant differences in any cardiac measures in the GH-treated vs. untreated groups (Table I). Fractional shortening, a measure of LV function, was also similar in the two groups. In addition, measures of diastolic function, E/A ratio (peak flow velocity in early diastole (E wave) and peak velocity at atrial contraction (A wave) and mitral deceleration time (DT), were normal and not significantly different between the groups. We further investigated if the duration of GH treatment affected cardiac dimensions. Thus, we used multiple regression analyses to evaluate the duration of GH treatment along with age and BSA as covariates (Table II). These analyses indicated that the number of years on GH did not independently influence cardiac growth. We also performed this analysis on the group currently on GH ( $\mathrm{n}=23)$ and obtained similar results (not shown).

\section{Discussion}

This study investigated the effects of GH treatment lasting an average of 4-5 years on cardiac dimensions in girls and young women with TS, using echocardiography to compare LV wall thickness and diameters in the 2 groups. As expected, the GH-treated group was significantly taller and cardiac dimensions were corresponding increased compared to age-matched untreated subjects. Adjusting for their larger body size, there were no significant differences in cardiac dimensions in the two groups. The fractional shortening, an index of LV function, was also similar in the two groups. These findings show that cardiac size in GH-treated girls with TS is proportionate to their increase in body size, suggesting that GH treatment, even in 
pharmacological doses, does not produce abnormal cardiac growth or hypertrophy in girls with TS.

An earlier study investigated the effects of 3 dosages of GH over 7 years in Dutch girls with TS, also by echocardiography (20). There was no untreated control group in this study, but cardiac dimensions were within the normal range for these girls and there was no apparent GH dose effect seen in the three different dosage groups. Another study compared cardiac measures in GH-treated girls with TS vs. age and size matched eukaryotic girls (24). They found no difference in LV mass or volume, but did report mild diastolic dysfunction among subjects with TS. However, these differences were likely attributable to significant differences in heart rate and blood pressure between the two groups. It is well established that the heart rate and blood pressure are on average higher in girls with TS compared to age-matched controls (25).

Although it is advantageous to have an untreated group with TS for comparison, a major drawback of our study is that groups were not randomly assigned. Thus there could be selection bias contributing to the findings. For example, if girls with cardiac involvement were selectively excluded from GH treatment by their caregivers, then the comparison might not be valid. However, the frequency of cardiovascular defects was similar in the two group, e.g., about $20 \%$ of each group had a bicuspid aortic valve. Also, it was abundantly clear that the major reason for non-treatment was late diagnosis because of suboptimal medical care, since the untreated girls were very short and generally as severely affected as the treated group. Finally, it is possible that adverse cardiovascular effects may not be apparent until more time has passed, and hence more long term follow-up is necessary to confirm the finding of no harmful effects of $\mathrm{GH}$ treatment on the cardiovascular system of patients with TS.

Our study establishes that pharmacological GH treatment has little effect upon LV size in patients with TS, at least over an intermediate (4-5 yr) period of observation. Thus we confirm the earlier studies that lacked control groups with TS, and extended our own previous study showing no apparent effect of GH on aortic diameter in TS (26). It is curious that there seems to be no cardio-selective effect by GH in girls with TS, although GH treatment of GH-deficient children has been associated with disproportionate left ventricular growth $(17,18)$. Perhaps this is because in GH deficiency there is a relative cardiac hypoplasia and associated catch-up growth with GH treatment. In any case, the present findings are reassuring that girls with TS are not especially vulnerable to GH-induced cardiac hypertrophy.

\section{Acknowledgements}

This work was supported by the intramural research program of the NICHD, NIH.

\section{References}

1. Nielsen J, Wohlert M. Chromosome abnormalities found among 34,910 newborn children: results from a 13-year incidence study in Arhus, Denmark. Hum Genet 1991;87:81-83. [PubMed: 2037286]

2. Lin AE, Lippe BM, Geffner ME, Gomes A, Lois JF, Barton CW, Rosenthal A, Friedman WF. Aortic dilation, dissection, and rupture in patients with Turner syndrome. J Pediatr 1986;109:820-826. [PubMed: 3772661]

3. Sybert VP. Cardiovascular Malformations and Complications in Turner Syndrome. Pediatrics 1998;101:e11. [PubMed: 9417175]

4. Bondy C. New Issues in the Diagnosis and Management of Turner Syndrome. Reviews in Endocrine \& Metabolic Disorders 2005;6:269-280. [PubMed: 16311945]

5. Bondy CA, Van PL, Bakalov VK, Sachdev V, Malone CA, Ho VB, Rosing DR. Prolongation of the cardiac QTc interval in Turner syndrome. Medicine (Baltimore) 2006;85:75-81. [PubMed: 16609345] 
6. Bondy CA, Ceniceros I, Van PL, Bakalov VK, Rosing DR. Prolonged Rate-Corrected QT Interval and Other Electrocardiogram Abnormalities in Girls With Turner Syndrome. Pediatrics 2006;118:e1220 1225. [PubMed: 17015510]

7. Gravholt CH, Hansen KW, Erlandsen M, Ebbehoj E, Christiansen JS. Nocturnal hypertension and impaired sympathovagal tone in Turner syndrome. J Hypertens 2006;24:353-360. [PubMed: 16508584]

8. Andersen NH, Hjerrild BE, Sorensen K, Pedersen EM, Stochholm K, Gormsen LC, Horlyck A, Christiansen JS, Gravholt CH. Subclinical left ventricular dysfunction in normotensive women with Turner's syndrome. Heart 2006;92:1516-1517. [PubMed: 16973807]

9. Soriano-Guillen L, Coste J, Ecosse E, Leger J, Tauber M, Cabrol S, Nicolino M, Brauner R, StaTur study g. Chaussain JL, Carel JC. Adult height and pubertal growth in Turner syndrome after treatment with recombinant growth hormone. J Clin Endocrinol Metab. 2005jc.2005-0470

10. Pasquino AM, Pucarelli I, Segni M, Tarani L, Calcaterra V, Larizza D. Adult height in sixty girls with Turner syndrome treated with growth hormone matched with an untreated group. J Endocrinol Invest 2005;28:350-356. [PubMed: 15966509]

11. The Canadian Growth Hormone Advisory C. Impact of Growth Hormone Supplementation on Adult Height in Turner Syndrome: Results of the Canadian Randomized Controlled Trial. J Clin Endocrinol Metab 2005;90:3360-3366. [PubMed: 15784709]

12. van Pareren YK, de Muinck Keizer-Schrama SM, Stijnen T, Sas TC, Jansen M, Otten BJ, HoorwegNijman JJ, Vulsma T, Stokvis-Brantsma WH, Rouwe CW, Reeser HM, Gerver WJ, Gosen JJ, Rongen-Westerlaken C, Drop SL. Final height in girls with turner syndrome after long-term growth hormone treatment in three dosages and low dose estrogens. J Clin Endocrinol Metab 2003;88:11191125. [PubMed: 12629094]

13. Colao A, Vitale G, Pivonello R, Ciccarelli A, Di Somma C, Lombardi G. The heart: an end-organ of GH action. Eur J Endocrinol 2004;151:S93-101. [PubMed: 15339252]

14. Maison P, Chanson P. Cardiac Effects of Growth Hormone in Adults With Growth Hormone Deficiency: A Meta-Analysis. Circulation 2003;108:2648-2652. [PubMed: 14623813]

15. Petersen KF, Oral EA, Dufour S, Befroy D, Ariyan C, Yu C, Cline GW, DePaoli AM, Taylor SI, Gorden P, Shulman GI. Leptin reverses insulin resistance and hepatic steatosis in patients with severe lipodystrophy. J Clin Invest 2002;109:1345-1350. [PubMed: 12021250]

16. Cittadini A, Berggren A, Longobardi S, Ehrnborg C, Napoli R, Rosen T, Fazio S, Caidahl K, Bengtsson BA, Sacca L. Supraphysiological Doses of GH Induce Rapid Changes in Cardiac Morphology and Function. J Clin Endocrinol Metab 2002;87:1654-1659. [PubMed: 11932297]

17. Shulman DI, Root AW, Diamond FB, Bercu BB, Martinez R, Boucek RJ Jr. Effects of One Year of Recombinant Human Growth Hormone (GH) Therapy on Cardiac Mass and Function in Children with Classical GH Deficiency. J Clin Endocrinol Metab 2003;88:4095-4099. [PubMed: 12970269]

18. Radetti G, Crepaz R, Paganini C, Gentili L, Pitscheider W. Medium-term cardiovascular effects of high-dose growth hormone treatment in growth hormone-deficient children. Horm Res 1999;52:247252. [PubMed: 10844415]

19. Radetti G, Crepaz R, Milanesi O, Paganini C, Cesaro A, Rigon F, Pitscheider W. Cardiac performance in Turner's syndrome patients on growth hormone therapy. Horm Res 2001;55:240-244. [PubMed: 11740146]

20. Sas TC, Cromme-Dijkhuis AH, de Muinck Keizer-Schrama SM, Stijnen T, van Teunenbroek A, Drop SL. The effects of long-term growth hormone treatment on cardiac left ventricular dimensions and blood pressure in girls with Turner's syndrome. Dutch Working Group on Growth Hormone. J Pediatr 1999;135:470-476. [PubMed: 10518081]

21. Schiller NB, Shah PM, Crawford M, DeMaria A, Devereux R, Feigenbaum H, Gutgesell H, Reichek N, Sahn D, Schnittger I, et al. Recommendations for quantitation of the left ventricle by twodimensional echocardiography. American Society of Echocardiography Committee on Standards, Subcommittee on Quantitation of Two-Dimensional Echocardiograms. J Am Soc Echocardiogr 1989;2:358-367. [PubMed: 2698218]

22. Devereux RB, Alonso DR, Lutas EM, Gottlieb GJ, Campo E, Sachs I, Reichek N. Echocardiographic assessment of left ventricular hypertrophy: comparison to necropsy findings. Am J Cardiol 1986;57:450-458. [PubMed: 2936235] 
23. de Simone G, Daniels SR, Devereux RB, Meyer RA, Roman MJ, de Divitiis O, Alderman MH. Left ventricular mass and body size in normotensive children and adults: assessment of allometric relations and impact of overweight. J Am Coll Cardiol 1992;20:1251-1260. [PubMed: 1401629]

24. Radetti, G.; Crepaz, R.; Milanesi, O.; Paganini, C.; Cesaro, A.; Rigon, F.; Pitscheider, W. Cardiac Performance in Turner's Syndrome Patients on Growth Hormone Therapy.

25. Nathwani NC, Unwin R, Brook CG, Hindmarsh PC. Blood pressure and Turner syndrome. Clin Endocrinol (Oxf) 2000;52:363-370. [PubMed: 10718835]

26. Bondy CA, Van PL, Bakalov VK, Ho VB. Growth Hormone Treatment and Aortic Dimensions in Turner Syndrome. J Clin Endocrinol Metab 2006;91:1785-1788. [PubMed: 16507631] 


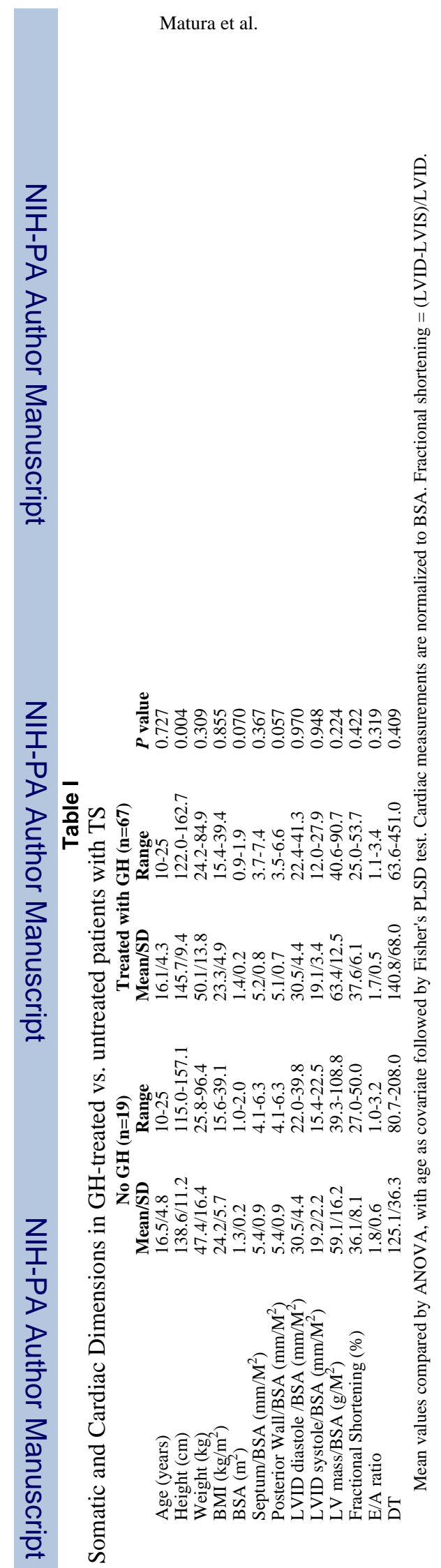

Page 7

年


Table II

Effect of GH Treatment on Septum, PW, LVID disastole, LVID systole, and LV mass Controlling for Age, Years on $\mathrm{GH}$, and BSA

\begin{tabular}{|c|c|c|c|c|}
\hline Cardiac Dimension & Estimate & SE & $t$ ratio & $p$ value \\
\hline $\begin{array}{l}\text { Septum } \mathrm{R}^{2}=0.246, p=0.0004 \\
\mathrm{n}=67 \\
\text { Intercept } \\
\text { Age } \\
\text { Years on GH } \\
\text { BSA }\end{array}$ & $\begin{array}{l}3.604 \\
0.013 \\
0.002 \\
2.363\end{array}$ & $\begin{array}{l}0.814 \\
0.039 \\
0.043 \\
0.800\end{array}$ & $\begin{array}{l}4.430 \\
0.335 \\
0.042 \\
2.952\end{array}$ & $\begin{array}{l}<0.0001 \\
0.739 \\
0.966 \\
0.004\end{array}$ \\
\hline $\begin{array}{l}\text { PW } \mathrm{R}^{2}=0.409, p=<0.0001 \\
\mathrm{n}=67 \\
\text { Intercept } \\
\text { Age } \\
\text { Years on GH } \\
\text { BSA }\end{array}$ & $\begin{array}{l}2.643 \\
-0.003 \\
-0.005 \\
3.172\end{array}$ & $\begin{array}{l}0.679 \\
0.033 \\
0.036 \\
0.668\end{array}$ & $\begin{array}{l}3.892 \\
-0.092 \\
-0.138 \\
4.748\end{array}$ & $\begin{array}{l}0.0002 \\
0.927 \\
0.891 \\
<0.0001\end{array}$ \\
\hline $\begin{array}{l}\text { LVID diastole } \mathrm{R}^{2}=0.222, p=0.001 \\
\mathrm{n}=67 \\
\text { Intercept } \\
\text { Age } \\
\text { Years on } \mathrm{GH} \\
\text { BSA }\end{array}$ & $\begin{array}{l}29.230 \\
0.045 \\
0.032 \\
8.422\end{array}$ & $\begin{array}{l}3.147 \\
0.151 \\
0.166 \\
3.096\end{array}$ & $\begin{array}{l}9.288 \\
0.300 \\
0.193 \\
2.720\end{array}$ & $\begin{array}{l}<0.0001 \\
0.765 \\
0.848 \\
0.008\end{array}$ \\
\hline $\begin{array}{l}\text { LVID systole } \mathrm{R}^{2}=0.116, p=0.050 \\
\mathrm{n}=67 \\
\text { Intercept } \\
\text { Age } \\
\text { Years on } \mathrm{GH} \\
\text { BSA }\end{array}$ & $\begin{array}{l}20.344 \\
0.022 \\
0.232 \\
3.140\end{array}$ & $\begin{array}{l}2.817 \\
0.135 \\
0.149 \\
2.771\end{array}$ & $\begin{array}{l}7.223 \\
0.162 \\
1.559 \\
1.133\end{array}$ & $\begin{array}{l}<0.0001 \\
0.872 \\
0.124 \\
0.261\end{array}$ \\
\hline $\begin{array}{l}\mathbf{L V} \text { mass } \mathrm{R}^{2}=0.017, p=0.778 \\
\mathrm{n}=67 \\
\text { Intercept } \\
\text { Age } \\
\text { Years on } \mathrm{GH} \\
\text { BSA }\end{array}$ & $\begin{array}{r}80.418 \\
-0.954 \\
-0.401 \\
14.317\end{array}$ & $\begin{array}{l}20.737 \\
0.996 \\
1.094 \\
20.399\end{array}$ & $\begin{array}{l}3.878 \\
-0.958 \\
-0.367 \\
0.702\end{array}$ & $\begin{array}{l}0.0003 \\
0.342 \\
0.715 \\
0.485\end{array}$ \\
\hline
\end{tabular}

